\section{Inpatient community groups with psychotic populations}

\section{DEAR SIRS}

Dr Novosel elequently described his experience of running a weekly Community Group on a long stay forensic ward (Bulletin, May 1986, 10, 105-107). His interesting publication is a rarity. Despite the fact that community groups are run routinely in many hospitals very little has been written about them. Considering the resources involved this is curious; I personally have in the past been involved in such groups run on a daily basis involving up to a dozen staff members for periods of one and a half hours (inclusive of 'debriefing').

With any treatment modality that is expensive in terms of staff resources it is important to be critical-have patients improved, does this improvement justify the costs involved and what were the side effects? Side effects occur with all treatments. Looking critically at Dr Novosel's group it must firstly be emphasised that it was run on a weekly basis and so was probably not overly expensive in terms of resources. Secondly, despite his claims for its success I could find no evidence in his writing to support this claim. Whether success is implied in terms of process or outcome variables it is important to determine by what criteria success - or lack of - can be judged.

His population was described as dangerous but no mention was made as to whether this dangerousness decreased or increased with this treatment modality. He asserts that details of personal histories were not suitable topics for conversation but later he describes considerable discussion regarding a patient's homosexuality. In my own experience I recall such a discussion regarding homosexuality which merely exacerbated psychotic symptoms in a patient who was afraid that he was homosexual. In another community group I recall staff enthusiastically persuading a violent child abusing schizophrenic mother to bring out into the open that she maltreated her children. She did so and received many nods of approval; however, within an hour or so of the group ending she became severely catatonic and remained that way for some days.

He describes in the early stages of the group the members being critical regarding being detained in hospital, of the psychiatrist and the hospital conditions. Was this criticism meant to imply improvement or worsening of members mental states? With such a population it must be asked did this really 'get their feelings off their chests' or did it in fact reinforce negative emotions and complaining behaviour; furthermore did it result in an increase in delusional persecutory ideation?

During the six month period he presumably took leave and at the end of the six months he terminated the group. The consequences he described included copious talk of 'nuclear wars ... Armageddon ... hopelessness ... no cure for mental illness ... Psychiatrists knew nothing ... (and) ... a sense of panic and confusion'. In conclusion, he asserts that the group was successful! If one were to have administered a depression rating scale at the beginning and towards the end of the six month period it would appear likely that the scale would have registered a profound increase in depressive symptoms. As to whether these symptoms occurred outside of the group setting and as to whether they persisted into the future, no mention is made.

The group was described as being a "valuable training experience". It is also said to have been therapeutic to staff. Although staff are not employed for their own personal therapy it is conceded that a productive milieu atmosphere should be actively cultivated. However, it has been my personal experience that such groups can serve as an arena for an alarming degree of institutionalised staff behaviour that may offset the more productive aspects of the group interaction. Whether community groups overall are productive or counter productive remains an open question which needs to be addressed empirically. Whilst appreciative of Dr Novosel's account of the group process it is suggested that it is long overdue for professionals to take an objective and critical look at this commonly used treatment modality with particular attention to the patient population under study. I suggest that such an approach might yield results which would indicate the usefulness or otherwise of specific types of groups for specific psychiatric disorders.

Valley Community Psychiatry Service

C. H. CANTOR

\section{Rosemount Hospital \\ c/o Royal Brisbane Hospital \\ Herston, Queensland, Australia}

\section{Dr Novosel replies:}

On running a group for psychotic patients in a maximum security hospital, I rapidly learned two things. Firstly that there was a very active 'world' within the perimeter fence which was full of complex and ever changing interactions and exchanges. Despite the very real nature of this inner world' there was a constant awareness of the outside world and the fact of detention preventing access to it. Secondly that it was impossible to separate the group from this 'inner world' within the perimeter fence. Much of my work as a therapist in the group was to contain and hold the group's anxiety. My initial task after the birth of the group was to create a safe setting whereby anxieties, either real or fantasy, could be expressed. Bearing in mind that all the patients were compulsorily detained in hospital, I consider that the expression of complaints during the early meetings was a necessary maturational stage in the life of the group and represented the patients testing my ability to contain their anxiety. Once the patients realised that the group was indeed a safe setting, these complaints disappeared and no longer dominated the meetings.

As the meetings progressed, it was evident that the group became part of the complex society within the perimeter fence and it would have been impossible, indeed undesirable, to avoid topics which were of major importance in this 'inner world'. Individual personal histories, especially reasons for admission to the State Hospital, were not discussed but the topic of homosexuality in a virtually all male 
institution, did not and could not fall into this category. The fact that this topic, amongst many others was openly and compassionately discussed again represented the safety of the group and the fact that anxiety could be contained.

At the end of any period of psychotherapy, it is appropriate that the patient experiences anxiety and depression. As the life of the group came to an end, these feelings were anticipated and this particular group of psychotic patients expressed their feelings in very concrete terms. However, again due to the safety of the group, this anxiety and depression was held and hence allowed the work of internalising the good experience of the group to take place.

Measuring success of psychotherapy with the mentally disordered offender is an important question which must be repeatedly raised. As indicated it was impossible and undesirable to separate the group from life within the hospital as a whole and I can only agree with Dr Murray Cox's statement that 'it is highly unlikely that psychotherapy "per se" could claim success or be blamed for failure'.

STEVEN Novosel

State Hospital

Carstairs Junction, Lanark

REFERENCE

Cox, M. (1986) The holding function of dynamic psychotherapy in a custodial setting: a review'. Journal of the Royal Society of Medicine, 79, 162-164.

\section{'Bridges over Troubled Waters' \\ DeAR SIRS}

As a Consultant Psychiatrist in Mental Handicap I feel obliged to comment on the NHS Health Advisory Service Report on Services for Disturbed Adolescents.

The report, although acknowledging the unsatisfactory state of affairs in the service provision for the adolescents with mental handicap, suggests very little in the way of remedies. It is all very well to say that adolescents with mental handicap should have access to the ordinary facilities but if ordinary facilities are not tailored to suit the needs of these people, outcome is less than satisfactory.

The Psychiatry of Mental Handicap Section of the Royal College of Psychiatrists has been forcefully advocating that the psychiatric needs of the mentally handicapped are special and cannot ordinarily be met within the general psychiatric set-up. The main reasons for this are:

(1) Most Regional Services are reluctant to accept mentally handicapped adolescents (mentally handicapped people being a minority in such a group may face scapegoating).

(2) Staff working in these adolescent units do not normally have training in the field of mental handicap.

(3) Some of the problems and needs of the mentally handicapped adolescents are different, e.g. chronologically they may be 12-19 but emotionally and intellectually they may be functioning at a much younger age. In fact some of the problems of adolescency like maturation, developing sexuality and the conflict of independence versus dependence are faced by mentally handicapped at a much later age than their normal counterparts. Because of adolescent unit's insistence on certain age group, these people miss out on these services.

In view of this may I suggest that either there should be separate facilities for adolescents with mental handicap or staff working with adolescents should have training in the field of the Psychiatry of Mental Handicap, or Consultant Psychiatrists in Mental Handicap should provide visiting Consultancy to these units on a regular basis.

\section{Leavesden Hospital}

IQBAL SINGH

\section{DeAr SIRS}

\section{MRCPsych Preliminary Test}

To some extent Dr Sevitt's suggestions (Bulletin, September 1986, 10, 248-249) have been incorporated in the revised MRCPsych Examination starting in the Autumn of 1987. Part I taken after the initial year's training will be a test in basic clinical psychiatry to include the subjects which all trainees should be learning - and teachers training - in their first year. Subsequently, in Part II, the relevant basic sciences will be tested along with clinical knowledge and skills. Details are set out in the Review Working Party's Report, which is available from the College.

There is not a 'fixed' pass rate for the Preliminary Test or the Membership Examination. Pass rates have fluctuated between approximately $45-60 \%$ in the past 10 years. All MCQ tests are 'peer referenced' so that the pass rate varies very little, but the other ingredients of the present Preliminary Test and of the Membership Examination are 'criterion referenced'. It is possible to make up for failure in the MCQ (but not of the Clinical) by good marks in other parts of the examination.

We make internal checks to see whether the MCQ is bringing down more and more bright candidates. In that case one would expect an increasing number of people with good essay marks to fail on their MCQ. There is no such evidence that this is happening. It is of course possible that there has been a general rise in the standard of the examination in the past 15 years, but not, I think, to an unwarranted extent. Some members might regard this as a change for the better.

J. L. T. BIRLEY Dean 